\title{
Case Report A Case of Valproate Induced Hyperammonemic Encephalopathy
}

\author{
Surjit Tarafdar, ${ }^{1}$ Mark Slee, ${ }^{2}$ Faisal Ameer, ${ }^{3}$ and Matt Doogue ${ }^{4}$ \\ ${ }^{1}$ Nephrology, Flinders Medical Centre, Bedford Park, SA 5042, Australia \\ ${ }^{2}$ Neurology, Flinders Medical Centre, Bedford Park, SA 5042, Australia \\ ${ }^{3}$ General Medicine, John Hunter Hospital, Newcastle, NSW 2305, Australia \\ ${ }^{4}$ Endocrinology/Clinical Pharmacology, Flinders Medical Centre, Bedford Park, SA 5042, Australia
}

Correspondence should be addressed to Surjit Tarafdar, gopubapi@rediffmail.com

Received 20 December 2010; Accepted 18 February 2011

Academic Editor: S. Kennedy

Copyright (c) 2011 Surjit Tarafdar et al. This is an open access article distributed under the Creative Commons Attribution License, which permits unrestricted use, distribution, and reproduction in any medium, provided the original work is properly cited.

\begin{abstract}
A 36-years-old man on phenytoin, levetiracetam, and sodium valproate presented with acute confusion. Routine investigations including serum valproate and phenytoin concentration were normal. His serum ammonia concentration was raised. His valproate was held and 2 days later he recovered with concordant normalisation of serum ammonia concentration. Urea acid cycle disorder was ruled out, and a diagnosis of valproate induced hyperammonemic encephalopathy (VHE) was made. Asymptomatic hyperammonemia occurs in $15-50 \%$ of valproate-treated patients, and while the true incidence of VHE is not known, it is a recognized complication of sodium valproate treatment. VHE typically presents acutely with impaired consciousness, lethargy, and vomiting. Valproate concentrations may be in the therapeutic range, and liver function tests are typically "normal." Treatment for VHE consists of ceasing valproate and providing supportive care. Some have advocated carnitine replacement.
\end{abstract}

Patients with valproate induced hyperammonemic Encephalopathy (VHE) may present with impaired consciousness, lethargy or increased seizure frequency. These patients may have normal liver function tests and plasma valproate concentration leading to the attending physician overlooking the diagnosis of VHE.

A 36-year-old man presented with acute confusion about 20 hours after an alcohol binge. Although he had long standing partial epilepsy, his partner had not observed any seizures and said this was unlike usual post ictal state. His regular medications were phenytoin $300 \mathrm{mg}$ twice daily, levetiracetam $500 \mathrm{mg}$ twice daily, and sodium valproate $1.5 \mathrm{~g}$ mane $2 \mathrm{~g}$ NOCTE. He had splenectomy 3 years previously for idiopathic thrombocytopenia with normal platelet counts since then. He was a current smoker and an alcohol binge drinker once or twice a month.

Findings at admission included normal physical examination, blood count, electrolytes, liver function tests, CRP, urinalysis, chest radiograph, ECG and head CT scan. Plasma ethanol $<0.01 \mathrm{~g} / \mathrm{dL}$ excluded acute alcohol intoxication and urine toxicology screen was negative. Plasma valproate was $52.9 \mathrm{mg} / \mathrm{L}$ (range $50-100 \mathrm{mg} / \mathrm{L}$ ) and plasma phenytoin $13.8 \mathrm{mg} / \mathrm{L}$ (range $10-20 \mathrm{mg} / \mathrm{L}$ ). Serum ammonia was high $-284 \mathrm{umol} / \mathrm{L}(<50 \mathrm{umol} / \mathrm{L})$. Valproate was withheld, his symptoms resolved over 24 hours, and on day 3 the serum ammonia was $36 \mathrm{umol} / \mathrm{L}$. Screening for urea cycle disorders was negative. A diagnosis of valproate induced hyperammonemic encephalopathy (VHE) was made.

The typical presentation of VHE is impaired consciousness and lethargy. Focal neurological symptoms and increased seizure frequency may be present [1]. The incidence of VHE is not known, but asymptomatic increases in serum ammonia are seen in $16 \%-52 \%$ of patients receiving valproate therapy [2]. VHE can occur with normal liver function tests and plasma valproate concentration [3].

Ammonia is eliminated by the urea cycle whose first ratelimiting step is mediated by carbamylphosphate synthetase 1 (CPS1). CPS1 in turn is activated by $\mathrm{N}$-acetylglutamate.

The metabolism of valproate by mitochondrial oxidation produces propionyl Co-A and valproyl Co-A, which inhibit $\mathrm{N}$-acetylglutamate synthetase with consequent depletion of $\mathrm{N}$-acetylglutamate. This leads to the inhibition of CPS1 resulting in decreased clearance of ammonia $[4,5]$. Another mechanism thought to play a role is the reduction of hepatic carnitine levels by valproate. Deficiency of carnitine results in decreased beta-oxidation of fatty acids, which in turn results 
in reduced levels of acetyl Co-A. Acetyl Co-A is a substrate for the $\mathrm{N}$-acetylglutamate synthetase mentioned above. Thus the decrease in acetyl Co-A ultimately disrupts the urea cycle resulting in ammonia accumulation [6].

Treatment for VHE includes supportive care and withholding valproate. L-carnitine replacement is sometimes used $[7,8]$. Extremely high concentrations of ammonia may warrant dialysis [9]. The diagnosis of VHE may be overlooked when the serum valproate concentration and liver function tests are within expected ranges. Physicians should be alert to this potential complication of valproate and measure serum ammonia in patients with alterations in mental status or unexplained increase in seizure frequency. Adjustment of dose or withdrawal of valproate may be necessary in the symptomatic patient in whom altered mental status is not due to seizure activity.

\section{References}

[1] V. Mittal, S. Muralee, and R. R. Tampi, "Valproic acid-induced hyperammonemia in the elderly: a review of the literature," Case Reports in Medicine, vol. 2009, Article ID 802121, 5 pages, 2009.

[2] P. Federico, S. Alqahanti, and R. P. Myers, "Possible new clinical sign of hyperammonemia," Canadian Medical Association Journal, vol. 178, no. 3, p. 326, 2008.

[3] J. Wadzinski, R. Franks, D. Roane, and M. Bayard, "Valproateassociated hyperammonemic encephalopathy," Journal of the American Board of Family Medicine, vol. 20, no. 5, pp. 499-502, 2007.

[4] M. F. Silva, C. C. Aires, P. B. Luis et al., "Valproic acid metabolism and its effects on mitochondrial fatty acid oxidation: a review," Journal of Inherited Metabolic Disease, vol. 31, no. 2, pp. 205-216, 2008.

[5] C. C. Aires, A. van Cruchten, L. Ijlst et al., "New insights on the mechanisms of valproate-induced hyperammonemia: inhibition of hepatic $\mathrm{N}$-acetylglutamate synthase activity by valproyl-Coa," Journal of Hepatology. In press.

[6] A. Rath, T. J. Naryana, G. V. S. Chowdhary, and J. M. K. Murthy, "Valproate-induced hyperammonemic encephalopathy with normal liver function," Neurology India, vol. 53, no. 2, pp. 226228, 2005.

[7] P. E. R. Lheureux, A. Penaloza, S. Zahir, and M. Gris, "Science review: carnitine in the treatment of valproic acid-induced toxicity-what is the evidence?" Critical Care, vol. 9, no. 5, pp. 431-440, 2005.

[8] S. Russell, "Carnitine as an antidote for acute valproate toxicity in children," Current Opinion in Pediatrics, vol. 19, no. 2, pp. 206-210, 2007.

[9] M. F. Tsai, C. Y. Chen, and K. C. Chiu, "Valproate-induced hyperammonemic encephalopathy treated by hemodialysis," Renal Failure, vol. 30, no. 8, pp. 822-824, 2008. 


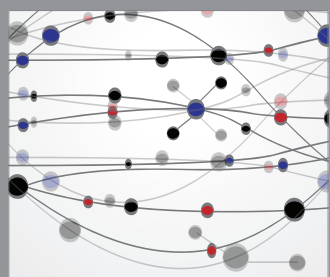

The Scientific World Journal
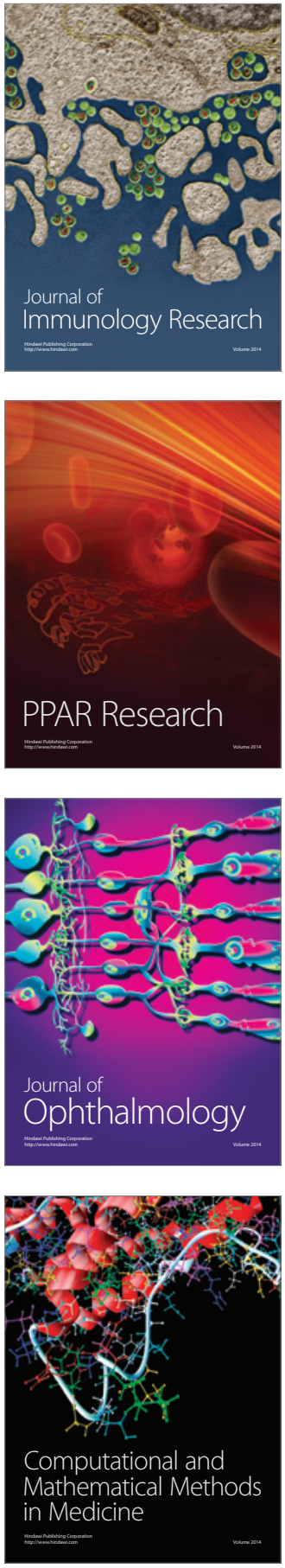

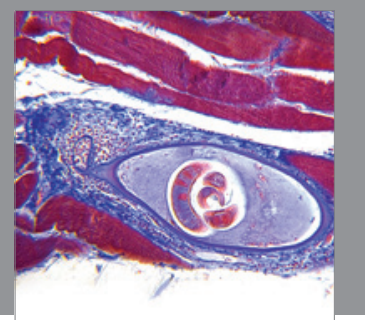

Gastroenterology

Research and Practice
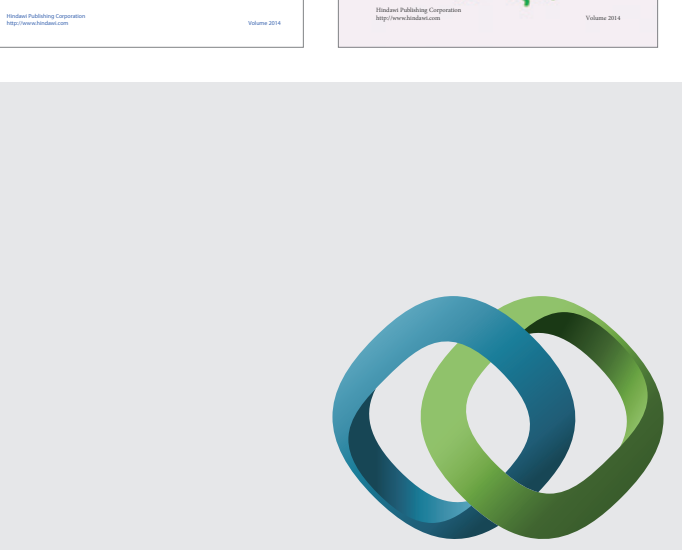

\section{Hindawi}

Submit your manuscripts at

http://www.hindawi.com
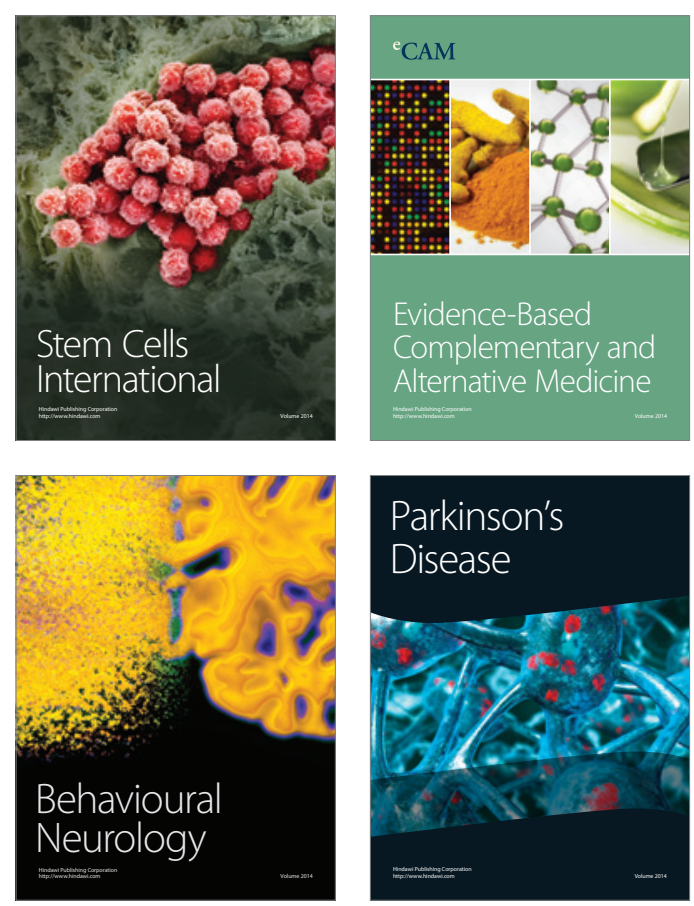

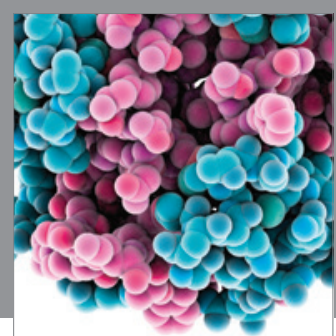

Journal of
Diabetes Research

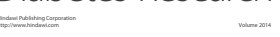

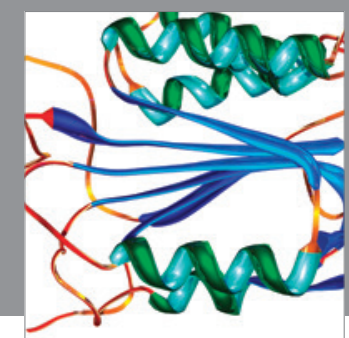

Disease Markers
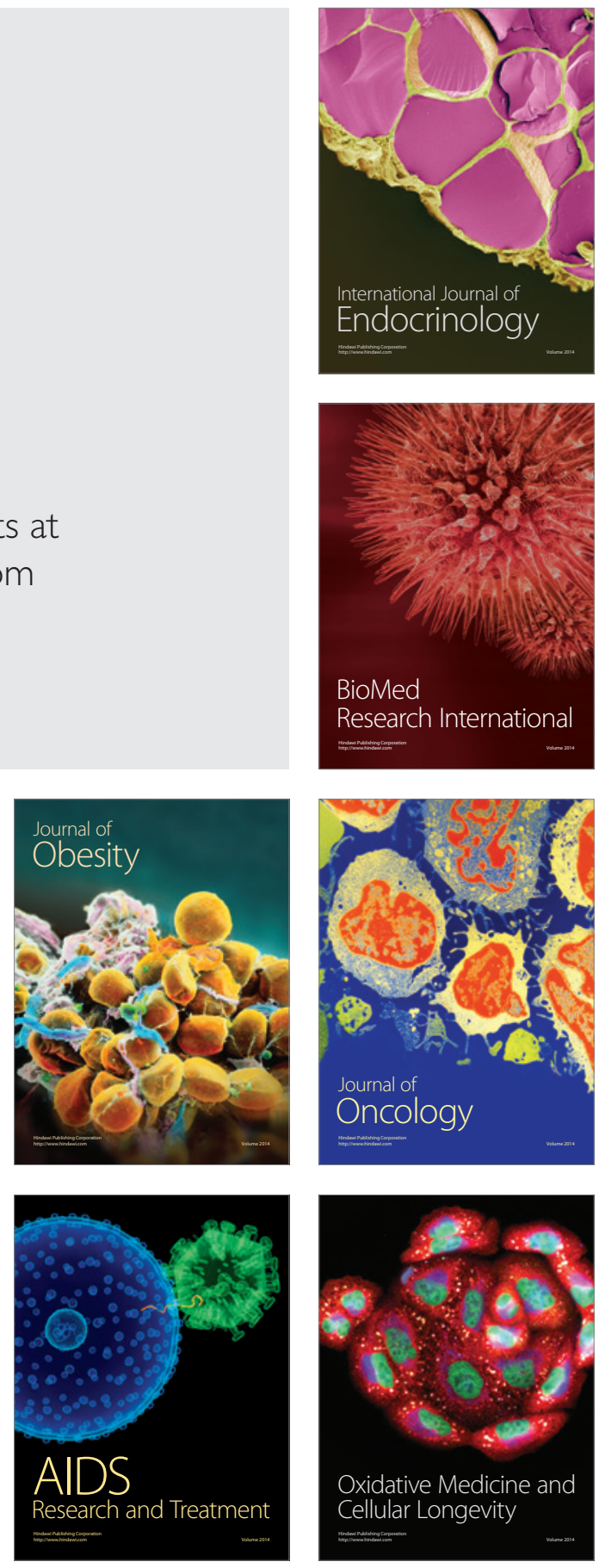